\title{
Teste de viabilidade e germinação de sementes de milho e feijão: uma proposta de atividade experimental de Botânica para o Ensino Médio
}

\author{
Viability test and germination of corn and beans seeds: a proposal for experimental botany activity \\ for High School \\ Prueba de viabilidad y germinación de semillas de maíz y frijol: propuesta de actividad botánica \\ experimental para la Escuela Secundaria
}

Recebido: 22/03/2021 | Revisado: 30/03/2021 | Aceito: 01/04/2021 | Publicado: 11/04/2021

Tiago Maretti Gonçalves

ORCID: https://orcid.org/0000-0001-8971-0647 Universidade Federal de São Carlos, Brasil

E-mail: tiagobio1@hotmail.com

\begin{abstract}
Resumo
A Botânica é uma das áreas das Ciências Biológicas que se preocupa em estudar a vida das algas e das plantas. Dotada de muitos termos, essa área é encarada por muitos alunos como complexa e tediosa. Para contornar essa problemática, o presente trabalho possui como principal objetivo facilitar e motivar a aprendizagem dos discentes na disciplina de Biologia, no Ensino Médio, no que tange aos tópicos da estrutura e função das sementes e de sua germinação nas angiospermas. Desse modo, a atividade proposta permite ao aluno trabalhar com materiais simples e de baixo custo como sementes de milho (Zea mays L.) e feijão (Phaseolus vulgaris L.), solução de Iodo à $5 \%$ e utensílios domésticos aplicados no teste de viabilidade de sementes e germinação. Assim, a atividade prática em questão permite ao professor abordar e discutir com os alunos não só tópicos de Botânica, mas também assuntos de Bioquímica, Fisiologia Vegetal e até mesmo aspectos da Agronomia. Dessa forma, a proposta da atividade experimental promove maior interesse dos alunos, facilitando a contextualização além de possibilitar a exploração do lado da experimentação científica.
\end{abstract}

Palavras-chave: Aula experimental; Sementes; Botânica; Teste de viabilidade de sementes; Germinação.

\begin{abstract}
Botany is one of the areas of Biological Sciences that is concerned with studying the life of algae and plants. Endowed with many terms, this area is seen by many students as complex and tedious. In order to get around this problem, the present work has as main objective to facilitate and motivate the learning of students in the discipline of Biology, in high school, regarding the topics of structure and function of seeds and yours germination in angiosperms. Thus, the proposed activity, allows the student to work with simple and low-cost materials such as corn seeds (Zea mays L.) and beans (Phaseolus vulgaris L.), 5\% Iodine solution and household utensils applied in the seed viability and germination. Thus, the practical activity in question, allows the teacher to approach and discuss with students not only the topics of Botany, but also subjects related to Biochemistry, Plant Physiology and even aspects related to Agronomy. In this way, the proposal of the experimental activity allows to promote greater interest of the students, facilitating its contextualization besides allowing the exploration on the side of the scientific experimentation.
\end{abstract}

Keywords: Experimental class; Seeds; Botany; Seed viability test; Germination.

\section{Resumen}

La botánica es una de las áreas de las Ciencias Biológicas que se ocupa de estudiar la vida de las algas y las plantas. Dotada de muchos términos, muchos estudiantes consideran que esta área es compleja y tediosa. Para sortear esta problemática, el presente trabajo tiene como principal objetivo facilitar y motivar el aprendizaje de los estudiantes de la disciplina de Biología, en la escuela secundaria, en los temas de estructura y función de las semillas e germinación en las angiospermas. Así, la actividad propuesta permite al alumno trabajar con materiales sencillos y de bajo costo como semillas de maíz (Zea mays L.) y frijol (Phaseolus vulgaris L.), solución de yodo al 5\% y utensilios domésticos aplicados en la viabilidad de la semilla e germanción. Así, la actividad práctica en cuestión, permite al docente acercarse y discutir con los alumnos no solo los temas de Botánica, sino también temas relacionados con Bioquímica, Fisiología Vegetal e incluso aspectos relacionados con la Agronomía. Así, la propuesta de la actividad experimental permite promover un mayor interés de los estudiantes, facilitando su contextualización además de permitir la exploración por el lado de la experimentación científica.

Palabras clave: Clase experimental; Semillas; Botánica; Ensayo de viabilidad de semillas; Germinación. 


\section{Introdução}

A Botânica (do grego botáne: planta, vegetal), é a área da Biologia que estuda e classifica os vegetais, considerando forma, estrutura e composição, agrupando-os em categorias de acordo com as características semelhantes (Trivelato \& Silva, 2011). Assim, essa área, no Ensino Médio, é encarada por parte representativa dos alunos como complexa por deter muitos termos que devem ser bem contextualizados. Outro ponto crítico consiste no predomínio de metodologias de ensino tradicional do tipo expositiva nas aulas, levando o aluno a decorar conceitos e fatos, sem se preocupar com o estabelecimento de relações e aspectos ligados a alfabetização científica (Bricia, 2014), o que pode desmotivar os discentes.

Para contornar essa situação, de modo a facilitar a aprendizagem do aluno e tornar as aulas atrativas e motivadoras, é importante a abordagem e utilização de metodologias alternativas de ensino (Gonçalves, 2021a), e uma delas é a proposta de aulas práticas experimentais na disciplina de Biologia no Ensino Médio.

Segundo Krasilchik (2004), as aulas experimentais no ensino de Biologia desempenham funções singulares tais como: permitir que os discentes tenham contato direto com os fenômenos, manipular os materiais e equipamentos, observar os organismos, analisar processos biológicos e verificar concretamente o significado da variabilidade individual e a consequente necessidade de se trabalhar com um número coletivo de indivíduos para validar os resultados. Neste sentido, Gonçalves (2021b), afirma que as aulas práticas possuem como principal potencialidade de permitir a aplicação dos conceitos vivenciados em aulas teóricas, facilitando a aprendizagem do tema proposto, além de promover a discussão e a proposição de hipóteses, despertando o lado da experimentação científica dos alunos.

No entanto, as aulas práticas de Ciências e Biologia ainda são pouco abordadas pelos professores. Segundo dados do Instituto Nacional de Estudos e Pesquisas Educacionais Anísio Teixeira, INEP (2019), apenas 38,8\% das escolas de ensino público possuem laboratórios de Ciências e Biologia para a realização de aulas práticas. Essa lacuna, no baixo uso de aulas experimentais no ensino pode estar relacionada com a escassez de recursos financeiros que recaem sobre o sistema público de ensino, inviabilizando a construção de laboratórios e compra de materiais. Diante disso, Marandino, Selles \& Ferreira (2009, p. 108), destacam que muitos professores desejam ampliar a oportunidade desse tipo de abordagem de ensino no seu cotidiano de trabalho, porém nem sempre alcançam sucesso, devido às dificuldades encontradas no âmbito escolar. Assim, essas dificuldades podem ser a inexistência de um laboratório físico para a realização dessas aulas, o tempo curricular, a insegurança de alguns professores e a falta de controle do grande número de alunos dentro do laboratório.

Desse modo, evidencia-se que essas são as razões propulsoras para a realização da proposta desse trabalho, com a utilização de materiais simples e de baixo custo, sem a necessidade de um laboratório físico equipado, promovendo a abordagem dos conteúdos de Biologia no Ensino Médio por meio de atividades práticas. Em detrimento da pandemia do novo coronavírus (Covid-19), os próprios alunos poderão efetuar os experimentos em casa, mediante instruções prévias pelo professor, por meio de uma aula virtual on-line. O professor poderá realizar a aula prática e depois, em suas casas, os discentes poderão repetir os experimentos, validando o que foi aprendido e em outro encontro, o professor poderá discutir os resultados com os alunos e sanar possíveis dúvidas.

Dessa forma, o principal objetivo deste trabalho é a proposta de uma aula prática utilizando materiais simples e de baixo custo, para facilitar a aprendizagem dos alunos em tópicos relacionados a Botânica, Bioquímica e Fisiologia Vegetal no $2^{\circ}$ ano do Ensino Médio. Deste modo, com a realização da atividade experimental, os discentes poderão fortalecer o que foi aprendido nas aulas teóricas de Biologia, permitindo o contato com a formulação de hipóteses e a experimentação científica. A primeira parte da atividade possui duração média de 30 a 40 minutos, e é recomendada aos alunos que estejam cursando o $2^{\circ}$ ano do Ensino Médio. Já a segunda parte poderá ser feita e acompanhada pelos alunos mediante a explicação prévia do 
professor durante 7 dias.

\section{Metodologia}

A atividade proposta possui caráter qualitativo com abordagem didático-experimental, e sua primeira parte, foi adaptada dos trabalhos de Marcos Filho, Cícero \& Silva (1987) e Sá, Oliveira \& Bertolin (2011).

\subsection{Materiais necessários para a condução da atividade}

Para a realização da aula prática proposta serão necessários os seguintes materiais:

-Copo graduado;

-Lugol 5\%;

-Sementes de milho;

-Sementes de feijão;

-Papel toalha e 1 coador;

- 2 copos de plástico de $50 \mathrm{ml}$ (para o teste de viabilidade de sementes);

- 2 copos de plástico de $50 \mathrm{ml}$ ou 2 pires (para a germinação do feijão e do milho).

\subsection{Preparo da solução de Lugol}

No copo graduado preencher $190 \mathrm{ml}$ de água e completar até $200 \mathrm{ml}$ com uma medida de $10 \mathrm{ml}$ de Lugol 5\%. Reservar essa solução no copo graduado (Figura 1) para o próximo passo da aula prática.

Figura 1. Solução de Lugol 5\% preparada. Notar a coloração marrom.

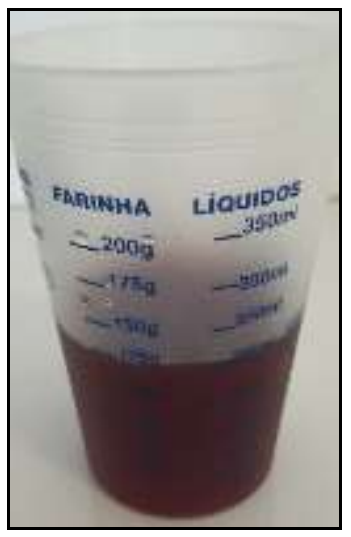

Fonte: Autor.

\subsection{Primeira parte: realizando o teste de viabilidade das sementes por meio da solução de Lugol $5 \%$}

Acondicionar as sementes de milho e feijão em copos separados. Para realização dessa etapa do experimento poderá ser utilizado por exemplo um número de 100 a 130 sementes de milho e de feijão. Após isso, preencher com a solução de Iodo preparada anteriormente até completar os dois copos contendo as sementes de milho e de feijão e deixar imersas nessa solução por aproximadamente 5 minutos. Retirar as sementes de milho da solução de água e Lugol com auxílio de um coador, colocálas na superfície do papel toalha para retirar o excesso, o mesmo deve ser feito com as sementes de feijão, separadamente.

Nesta etapa, o professor pode sugerir aos alunos que observem o aspecto físico das sementes (coloração), registrando 
os resultados no caderno. Após isso, pode ser sugerido também, que os alunos formulem hipóteses em relação a coloração das sementes, confrontando o porquê desse acontecimento e fazer uma comparação com as sementes que não foram coradas.

Pedir aos alunos que separem as sementes de milho não coradas daquelas que ficaram intensamente coradas (coloração intensamente azul escuro), o mesmo deve ser feito com as sementes de feijão. Depois de proceder a separação mecânica, os alunos irão realizar o cálculo de proporção entre as sementes coradas e não coradas, para isso, sugere-se a confecção de uma tabela para registro desses resultados (Tabela 1).

Tabela 1. Proporções de sementes coradas (lesionadas) das não coradas (intactas) pelo tesde de Lugol 5\%.

\begin{tabular}{|c|c|c|c|c|c|}
\hline Tratamento & $\begin{array}{c}\mathbf{N}^{\mathbf{0}} \text { de } \\
\text { sementes não } \\
\text { coradas }\end{array}$ & $\begin{array}{c}\% \\
\text { de sementes } \\
\text { não coradas }\end{array}$ & $\begin{array}{c}\mathbf{N}^{0} \text { de } \\
\text { sementes } \\
\text { coradas }\end{array}$ & $\begin{array}{c}\% \\
\text { de sementes } \\
\text { coradas }\end{array}$ & $\begin{array}{c}\text { Total de } \\
\text { sementes } \\
\text { analisadas }\end{array}$ \\
\hline Milho & & & & & \\
\hline Feijão & & & & & \\
\hline
\end{tabular}

Fonte: Autor (2021).

\subsection{Segunda parte: germinação e crescimento de sementes de milho e feijão intactas em meio de papel toalha umedecido.}

$\mathrm{Na}$ segunda etapa da atividade experimental, o professor pode sugerir aos alunos que escolham algumas sementes intactas (não coradas pelo Lugol pelo teste anterior) para o plantio, no meio contendo papéis toalha umedecidos. Pode ser escolhido também, outras sementes próprias para o plantio, com o intuito de acompanhar o processo de germinação. Assim, as sementes devem ser colocadas sobre papéis toalha umedecidos, e recobertas com outra camada sendo bastante umedecidas com água. Molhar os tratamentos pelos menos 2 vezes ao dia e mantê-los durante bastante luz, durante pelos menos 7 dias. Anotar os resultados dos acontecimentos conforme a Tabela 2. Na Tabela 3, os alunos deverão respondê-la após conclusão da segunda parte da atividade prática mediante a discussões com o professor.

Tabela 2. Fenômenos observados na germinação de sementes intactas de milho e feijão.

\begin{tabular}{|c|c|c|}
\hline Dia & \multicolumn{2}{|c|}{ Anotações/Observações } \\
\hline 1 & Milho & \\
\hline 2 & & \\
\hline 3 & & \\
\hline 4 & & \\
\hline 5 & & \\
\hline 6 & & \\
\hline 7 & & \\
\hline
\end{tabular}

Fonte: Autor (2021). 
Tabela 3. Características gerais das espécies estudadas.

\begin{tabular}{|l|l|l|l|l|}
\hline \multicolumn{1}{|c|}{ Características } & \multicolumn{1}{c|}{ Milho } & \multicolumn{2}{c|}{ Feijão } \\
\hline Nome da espécie & & \multicolumn{2}{|l|}{} \\
\hline $\begin{array}{l}\text { Classificação botânica quanto aos } \\
\text { Cotilédones }\end{array}$ & $\begin{array}{l}\text { Monocotiledônea } \\
\text { Dicotiledônea }\end{array}$ & & $\begin{array}{l}\text { Monocotiledônea } \\
\text { Dicotiledônea }\end{array}$ & \\
\cline { 3 - 5 } & Tipo de germinação & & & \\
\hline Distribuição de vasos no caule & & & \\
\hline Tipo de raiz & & & \\
\hline Tipo de caule & & \\
\hline Tipo de nervação foliar & & \\
\hline
\end{tabular}

Fonte: Autor (2021).

\section{Resultados e Discussão}

Como fruto da presente atividade, o que podemos evidenciar nas sementes de milho e feijão submetidas ao teste de viabilidade por meio do Lugol 5\%? Na Figura 2 tem-se os resultados respectivamente para as sementes de milho e feijão.

$\mathrm{Na}$ literatura, o teste de viabilidade de sementes por meio do Lugol 5\% possui como principal função distinguir sementes com injúrias mecânicas das sementes intactas. O fato de algumas sementes de milho (Figura $2 \mathrm{~b}$ e $2 \mathrm{c}$ ) e feijão (Figura 2e e 2f) exibirem coloração azul escuro intenso está relacionado a ocorrência de injúrias mecânicas. Explicar aos alunos que essas lesões são problemas sérios enfrentados por muitos agricultores ao procederem as sementes para o plantio, resultando em redução do vigor e até mesmo do poder de germinação (Carvalho \& Nakagawa, 2012). Assim, a injúria mecânica pode ser causada em detrimento de choques e, ou atritos das sementes contra superfícies duras ou contra outras sementes, o que resultam em sementes quebradas, trincadas, fragmentadas, arranhadas ou inteiramente danificadas (Ferreira, 2010).

E o que leva o aparecimento da coloração azul escuro intensa nas sementes lesionadas? Explicar aos alunos que isso se deve a complexação da solução de Lugol 5\% na estrutura química do amido na semente. Neste caso, as sementes lesionadas poderão expor parte do seu embrião ou do endosperma (Carvalho \& Nakagawa, 2012).

No caso do endosperma, estrutura encontrada na semente que resulta da fusão dos núcleos polares com um dos núcleos reprodutivos do grão de pólen, é composto basicamente de amido e hemiceluloses (carboidratos do tipo polissacarídeos) (Carvalho \& Nakagawa, 2012). Assim, o Lugol, composto pelo Iodo irá se complexar na estrutura química molecular desses polissacarídeos das sementes com injúrias, resultando em uma ligação do tipo íon-dipolo, exibindo uma coloração azul escuro intensa (Figura 3).

No aspecto da Bioquímica, essa atividade permite ao professor abordar e discutir com os alunos sobre os carboidratos nas plantas, principalmente os polissacarídeos como o amido, a amilose, a amilopectina, e a celulose. Vale a pena ressaltarmos que, o amido, é um polissacarídeo produzido em grande quantidade nas plantas, e é constituído por dois outros polissacarídeos que possuem estruturas moleculares diferentes como a amilose e amilopectina (Figura 4a e Figura 4b).

A molécula da amilose não possui ramificações e, no espaço, assume conformação helicoidal (forma de hélice). A amilopectina apresenta ramificações, sendo que os "ramos" aparecem a cada 24-30 moléculas de glicose. Assim, essas moléculas podem sofrer reações de complexação do amido com o iodo formando um complexo de cor azul intensa. (Laboratório Didático de Bioquímica, 2017). 
Research, Society and Development, v. 10, n. 4, e29510414120, 2021

(CC BY 4.0) | ISSN 2525-3409 | DOI: http://dx.doi.org/10.33448/rsd-v10i4.14120

Figura 2. Resultados obtidos por meio da solução preparada de Lugol à 5\%. a) sementes de milho (Zea mays L.) exibindo ausência de coloração; b) sementes de milho coradas com Lugol; c) seta indicando sementes de milho ampliadas para melhor visualização; d) sementes de feijão (Phaseolus vulgaris L.) não coradas; e) sementes de feijão coradas com Lugol 5\%. f) ampliação semente de feijão corada com Lugol.

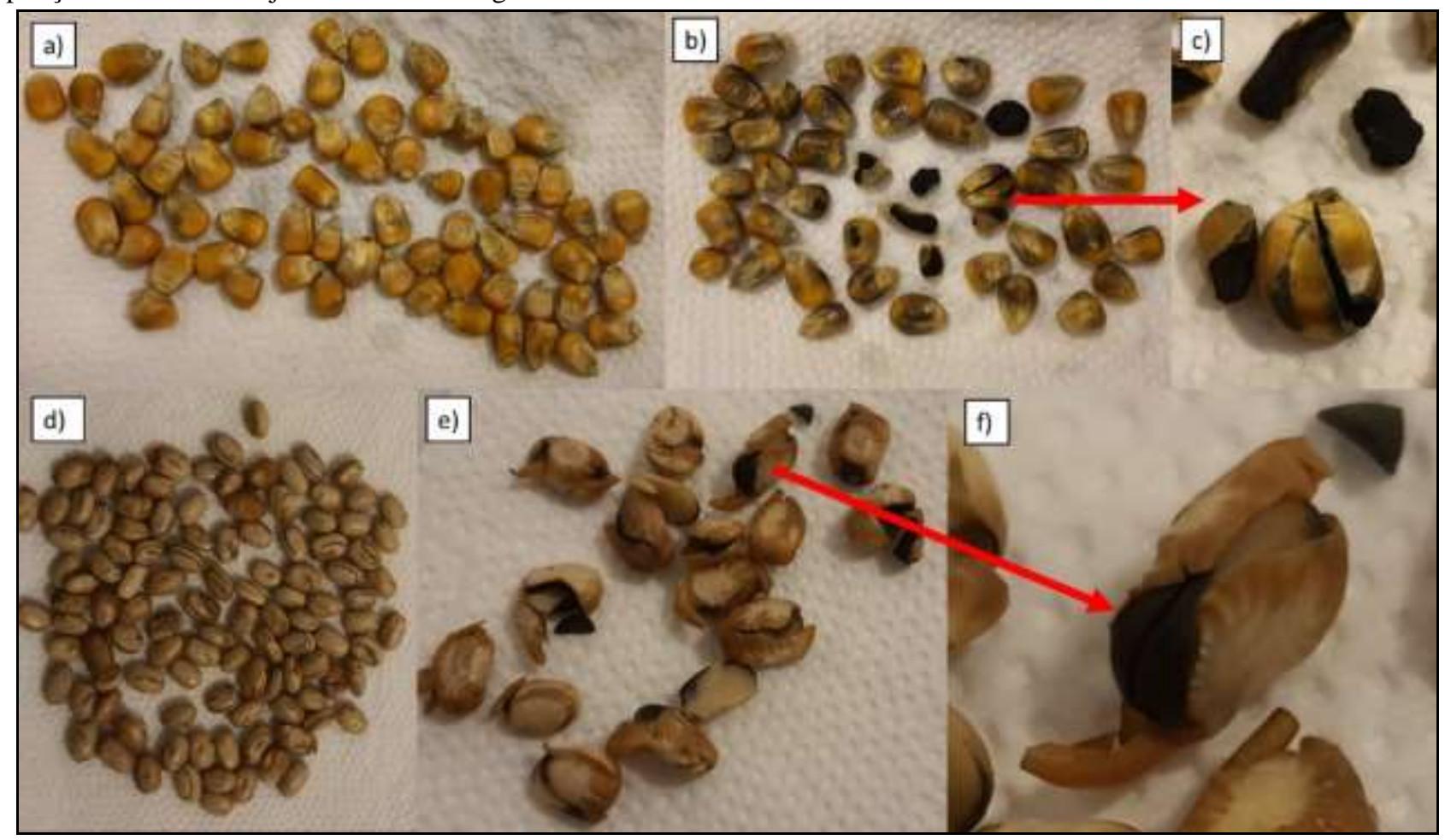

Fonte: Autor (2021).

Figura 3. Ligação química do tipo íon-dipolo, que decorre da complexação do Iodo com a estrutura molecular do amido no endosperma das sementes injuriadas, levando a coloração azul escuro intenso.

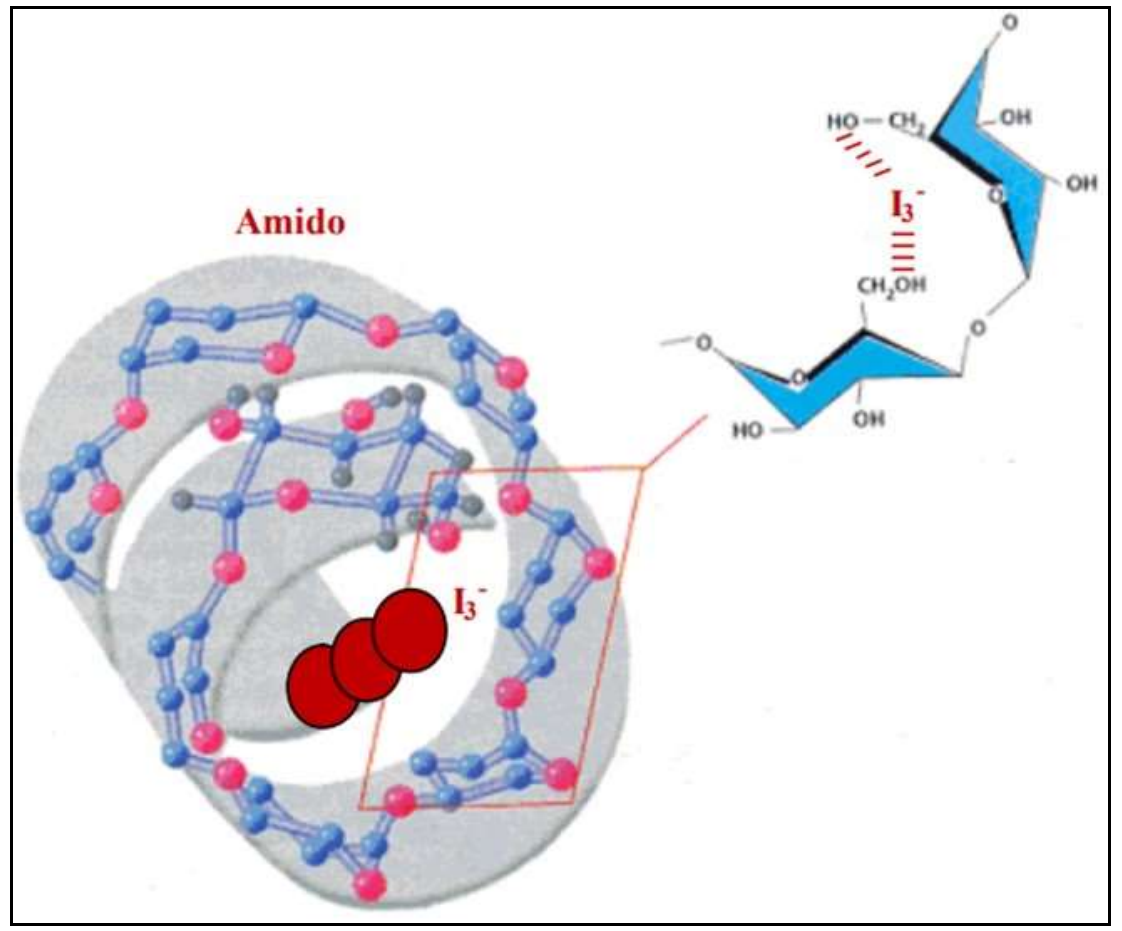

Fonte: Ferreira, Costa \& Araújo (2008). 
Para Reece et al. (2015), tanto as plantas como os animais armazenam açucares para o seu uso posterior na forma de polissacarídeos. No caso das plantas, o amido é armazenado como grânulos no interior de estruturas celulares denominadas de plastídeos, incluindo os cloroplastos. Assim, segundo os autores, a síntese de amido permite as plantas armazenarem uma fonte extra de glicose. Já a celulose, outro polissacarídeo encontrado nas plantas, se dispõem como microfibrilas constituindo o principal componente que circunda a resistente parede celular dos vegetais (Reece et al., 2015).

Os professores devem abordar com os alunos sobre a estrutura e função das sementes maduras. Segundo Carvalho \& Nakagawa (2012), as sementes das Angiospermas são constituídas basicamente por tegumento e embrião (cotilédone(s) + eixo embrionário) e um terceiro constituinte denominado endosperma, que às vezes pode estar ausente. Além disso, do ponto de vista funcional, as sementes são constituídas por casca (cobertura de proteção), tecido de reserva (endospermático ou cotiledonar, ou perispermático) e tecido meristemático (eixo embrionário), sendo que cada uma dessas partes possuem funções específicas. No quadro abaixo, estão dispostos de maneira sucinta as estruturas e suas respectivas funções presentes nas sementes das Angiospermas.

Figura 4. Estruturas moleculares do amido. a) amilose e b) amilopectina

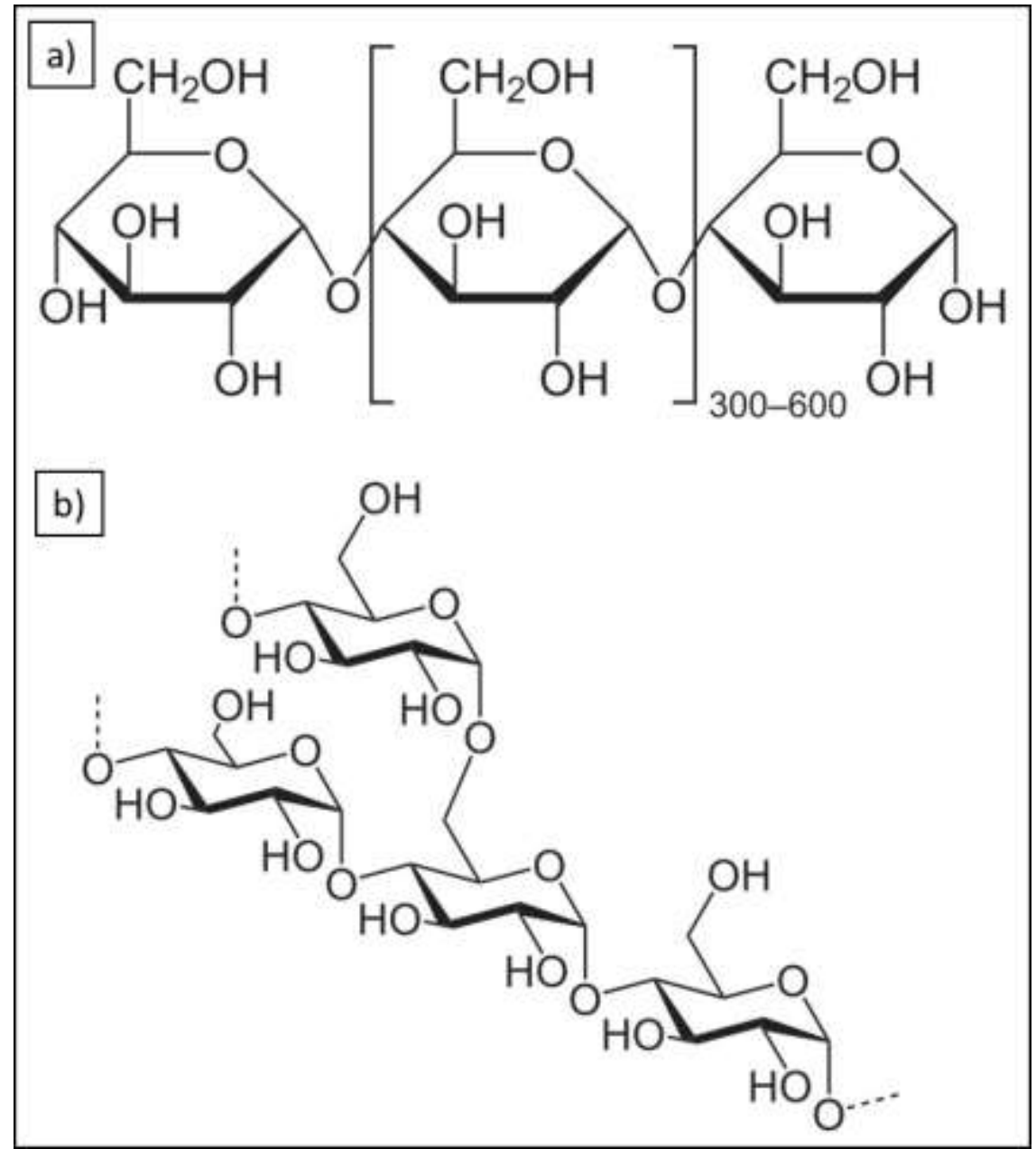

Fonte: a) Wikipedia (2021a). Foto de NEUROtiker. https://pt.wikipedia.org/wiki/Amilose\#: :text=Amilose\%20\%C3\%A9\% 20uma\% 20mol\%C3\% A9cula\%20formada,pol\%C3\%ADmero\%20que\%20forma\%20o\%20amido.

b) Wikipedia (2021b). Foto de NEUROtiker. https://pt.wikipedia.org/wiki/Amilopectina\#: :text=A\%20amilopectina $\% 2 \mathrm{C} \% 20 \mathrm{~mol} \%$ C3\%A9cula \%20mais\%20abundante,liga\%C3\%A7\%C3\%B5es\%20\%CE\%B1\%2D1\%2C6. 
Quadro 1. Principais estruturas das sementes e suas funções.

\begin{tabular}{|c|c|}
\hline Estrutura na semente & Funções \\
\hline $\begin{array}{l}\text { Casca (pode ser composta } \\
\text { apenas pelo tegumento, ou } \\
\text { então também pelo pericarpo) }\end{array}$ & $\begin{array}{c}\text { - Proteção da semente; } \\
\text { - Promover a impermeabilização da semente; } \\
\text { - Regular a germinação por meio do mecanismo da dormência; } \\
\text { - Regular velocidade das trocas gasosas }\end{array}$ \\
\hline Endosperma & Desempenha a função de nutrição. \\
\hline Cotilédones & $\begin{array}{l}\text { - Síntese de reservas alimentares; } \\
\text { - Armazenamento de reservas alimentares; } \\
\text { Realização de fotossíntese; }\end{array}$ \\
\hline Perisperma & $\begin{array}{l}\text { - Local que ocorre reserva nutritiva, ocorrendo principalmente na } \\
\text { Beterraba (Beta vulgaris). }\end{array}$ \\
\hline Eixo embrionário & $\begin{array}{c}\text { - Possui o tecido mesristemático, que por meio de divisões celulares } \\
\text { permite crescimento nos dois sentidos (o das raízes e o da plúmula) } \\
\text { originando uma plântula. }\end{array}$ \\
\hline
\end{tabular}

Fonte: Carvalho \& Nakagawa (2012).

O cálculo das proporções de viabilidade das sementes intactas (não coradas) e das sementes com lesões (coradas) estão dispostos na tabela abaixo. Nas sementes de milho, em relação ao feijão, ocorreu maior taxa de sementes lesionadas $(41,12 \%)$, podendo estar relacionado principalmente no meio de transporte ou acondicionamento que essas sementes foram submetidas.

Tabela 4. Resultados das proporções de sementes coradas (injuriadas) das não coradas (intactas) pelo teste de Lugol 5\%.

\begin{tabular}{|c|c|c|c|c|c|c|}
\hline Tratamento & $\begin{array}{c}\mathbf{N}^{\mathbf{0}} \text { de } \\
\text { sementes } \\
\text { não coradas }\end{array}$ & $\begin{array}{c}\mathbf{\%} \\
\text { de sementes } \\
\text { não coradas }\end{array}$ & $\begin{array}{c}\mathbf{N}^{\mathbf{0}} \text { de } \\
\text { sementes } \\
\text { coradas }\end{array}$ & $\begin{array}{c}\% \\
\text { de sementes } \\
\text { coradas }\end{array}$ & $\begin{array}{c}\% \\
\text { Total }\end{array}$ & $\begin{array}{c}\text { Total de } \\
\text { sementes } \\
\text { analisadas }\end{array}$ \\
\hline Milho & 63 & $58.87 \%$ & 44 & $41.12 \%$ & $100 \%$ & 107 \\
\hline Feijão & 110 & $88.0 \%$ & 15 & $12.0 \%$ & $100 \%$ & 125 \\
\hline
\end{tabular}

Fonte: Autor (2021).

$\mathrm{Na}$ segunda parte da atividade, temos abaixo as fotos com os principais acontecimentos no processo de germinação das sementes de milho e feijão, bem como os resultados discutidos dia após dia no processo de germinação das sementes que foram selecionadas no teste de viabilidade por meio da solução de Lugol à 5\%. Nessa parte, o professor poderá discutir com os alunos os resultados no âmbito tanto da Botânica como também da área da Fisologia Vegetal, discutindo com os alunos os principais eventos que acontecem no mecanismo da germinação bem como por exemplo do advento da dormência que algumas sementes exibem.

Inicialmente, deve ser comentado com os alunos a respeito dos eventos gerais que ocorrem no processo de germinação das plantas. De acordo com Bresinsky et al., (2012), a germinação é o processo em que, a semente absorve água e incha, e os tecidos internos rompem a sua casca (ou também a parede do fruto) e ao mesmo tempo, o embrião começa a se desenvolver e a degradar as substâncias nutritivas.

Nos resultados da atividade proposta, no primeiro dia, ocorreu no milho a emissão da primeira radícula e o aparecimento da coleorriza (Figura 5a). A radícula constitui uma importante estrutura vegetal, uma vez que será a futura raiz da planta. Já a coleorriza é uma estrutura em formato de bainha que recobre a radícula nas monocotiledôneas. Já no feijão (Figura 5b), ocorreu o aparecimento das primeiras radículas. 
Research, Society and Development, v. 10, n. 4, e29510414120, 2021

(CC BY 4.0) | ISSN 2525-3409 | DOI: http://dx.doi.org/10.33448/rsd-v10i4.14120

Comentar com os alunos que o processo de germinação é influenciado por vários aspectos como por exemplo fatores internos como a longevidade e viabilidade e fatores externos como a disponibilidade de água, temperatura e oxigênio. (Carvalho e Nakagawa, 2012). Em relação ao fator externo "água”, a absorção desse líquido resulta na reidratação dos tecidos com a consequente intensificação da respiração e de todas as outras atividades metabólicas que levam o fornecimento de energia e nutrientes para o desenvolvimento da semente (Carvalho \& Nakagawa, 2012). Evidenciar aos alunos que ao colocarmos água na semente ela fica entumescida, promovendo o rompimento da casca.

Figura 5. Germinação das sementes de milho (a) e do feijão (b), primeiro dia.

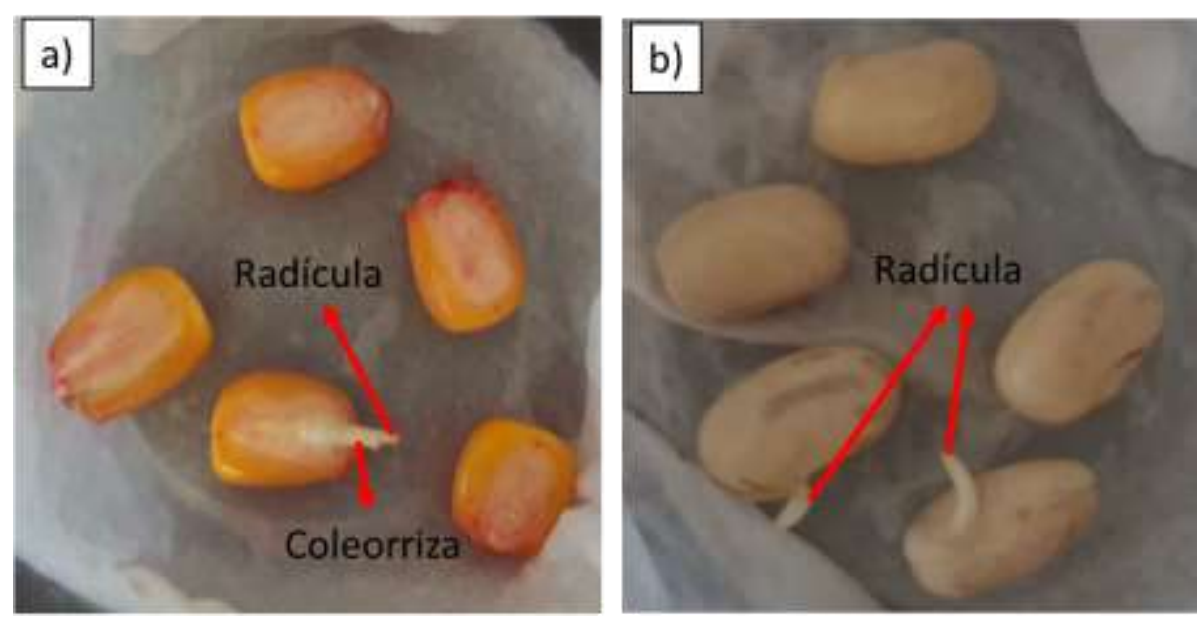

Fonte: Autor (2021).

No segundo dia (Figura 6), no milho, houve o aparecimento de raízes secundárias, de pelos na radícula, e o aparecimento do coleóptilo e da plúmula. O coleóptilo é definido como uma estrutura de origem foliar, caracterizado por estar presente em embriões de gramíneas e é a primeira estrutura emergente dessas plantas capaz de buscar a luz (Gonçalves \& Lorenzi, 2011). Já a plúmula, é constituída pelo conjunto do ápice caulinar de um embrião em início de germinação, geralmente sendo provido de os primórdios foliares da planta (Gonçalves \& Lorenzi, 2011). Já, no feijão, ocorreu o desenvolvimento das radículas.

Figura 6. Germinação das sementes de milho (a) e do feijão (b), segundo dia.

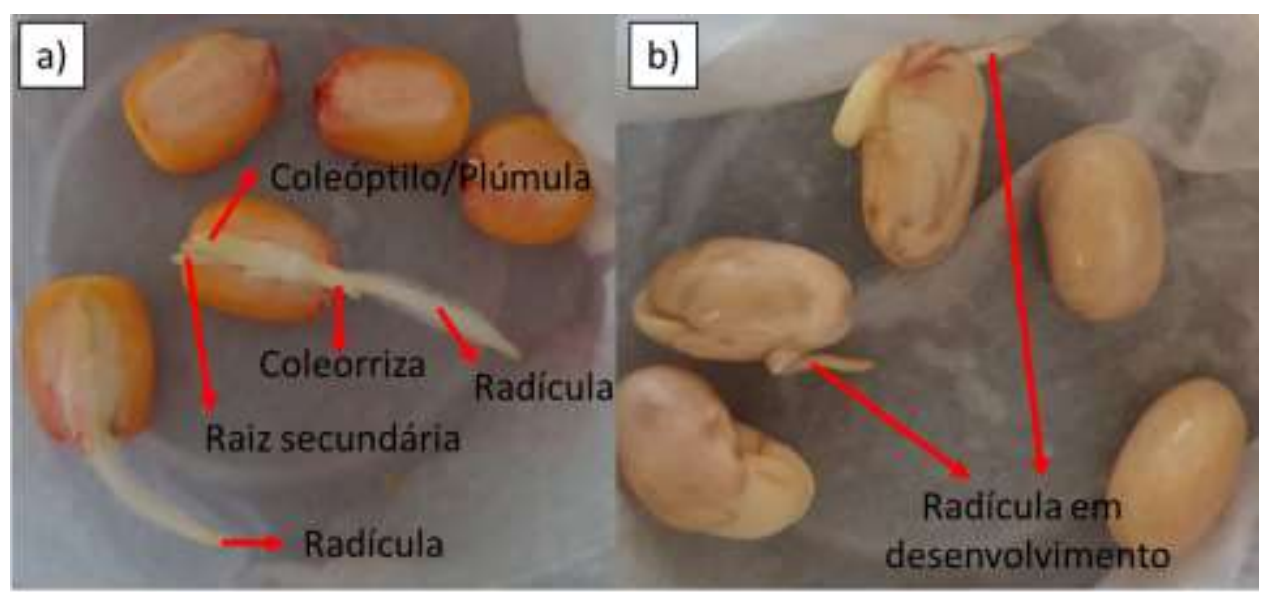

Fonte: Autor (2021). 
Research, Society and Development, v. 10, n. 4, e29510414120, 2021

(CC BY 4.0) | ISSN 2525-3409 | DOI: http://dx.doi.org/10.33448/rsd-v10i4.14120

No terceiro dia, no milho (Figura 7a), houve desenvolvimento das radículas e do coleóptilo, sendo este último tendo se desenvolvido principalmente na sua porção medial (mesocótilo). Ocorreu o aparecimento das raízes secundárias. No feijão (Figura 7b), a radícula continuou a se desenvolver, e ocorreu o desenvolvimento do hipocótilo.

Figura 7. Germinação das sementes de milho (a) e do feijão (b), terceiro dia.

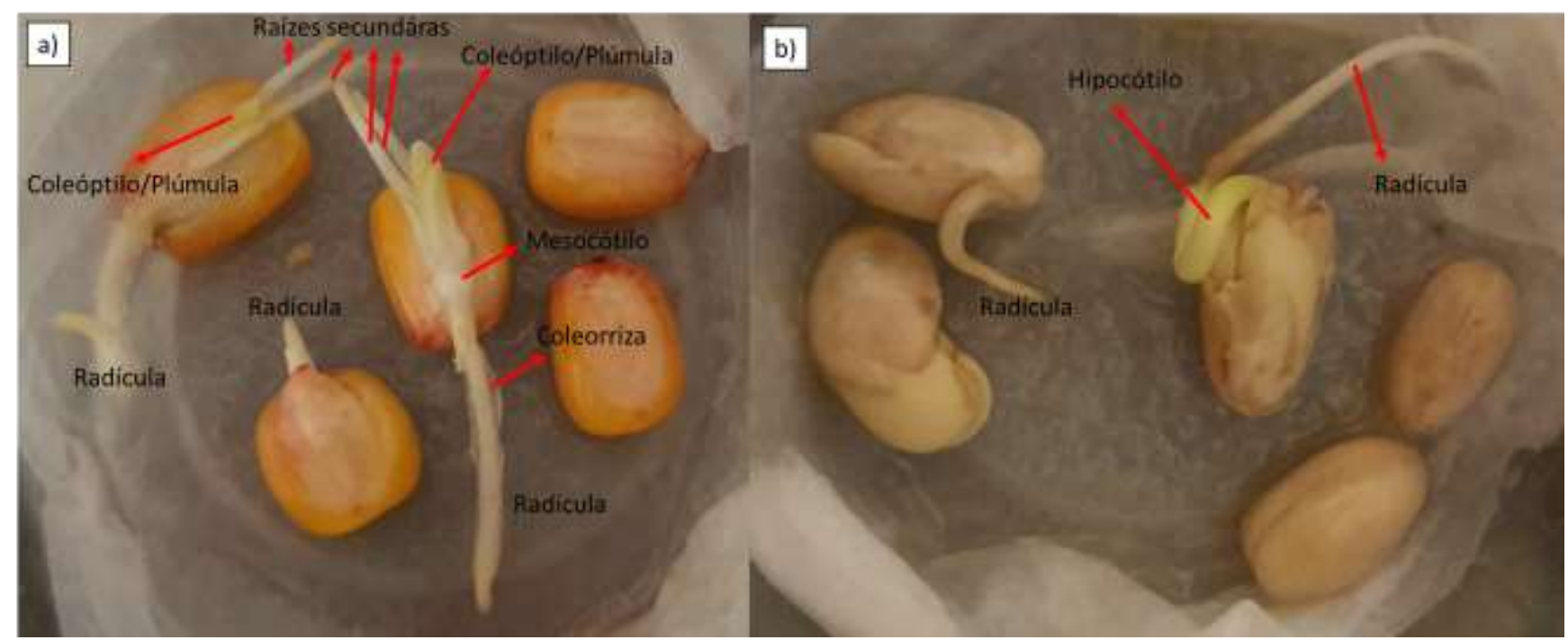

Fonte: Autor (2021).

No quarto dia, no milho (Figura 8a), houve desenvolvimento de todas as estruturas. Já no feijão (Figura 8b), ocorreu o desenvolvimento da radícula, formação de raízes secundárias e o hipocótilo se tornou mais desenvolvido. Neste estágio, houve o aparecimento dos cotilédones. Comentar com os alunos que essa estrutura é de grande importância na classificação das angiospermas, uma vez que conforme Peter, Evert \& Eichhorn (2001), as plantas classificadas como monocotiledôneas apresentam um único cotilédone (no caso do milho), e as dicotiledôneas (no caso do feijão) possuem dois cotilédones como pode ser observado na Figura 8.

Figura 8. Germinação das sementes de milho (a) e do feijão (b), quarto dia.

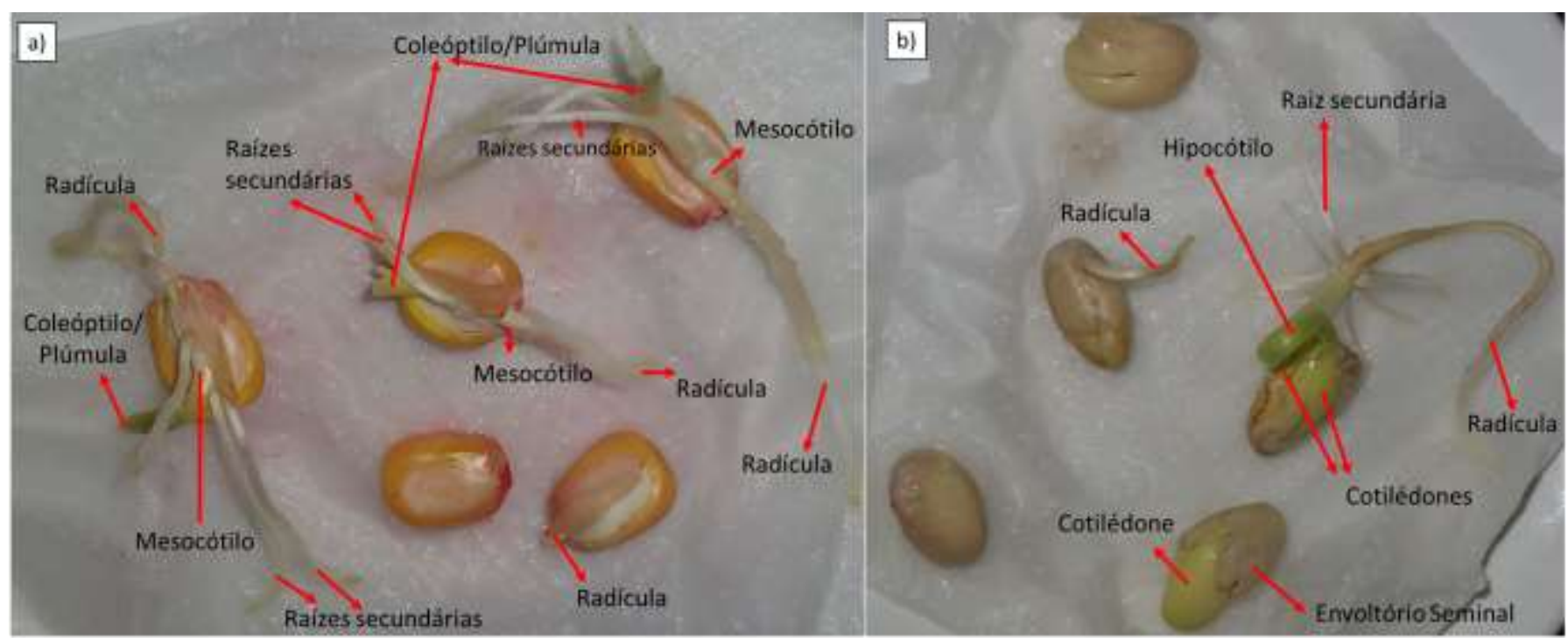

Fonte: Autor (2021). 
Research, Society and Development, v. 10, n. 4, e29510414120, 2021

(CC BY 4.0) | ISSN 2525-3409 | DOI: http://dx.doi.org/10.33448/rsd-v10i4.14120

É importante ressaltar aos alunos a diferença entre germinação epígea e hipógea. Segundo Nabors (2014), a germinação do tipo epígea (do grego "sobre a terra"), o hipocótilo cresce e empurra os cotilédones acima da superfície do solo e os cotilédones funcionam inicialmente como órgãos fotossintetizantes. Já a germinação hipógea (do grego "embaixo da terra), os cotilédones permanecem abaixo do nível do solo.

No quinto dia, no milho (Figura 9a e 9b), houve desenvolvimento dos coleóptilos e a emergência do primeiro primórdio foliar, além do desenvolvimento das radículas e maior crescimento de pelos nas raízes secundárias. No feijão (Figura 9c), houve o aparecimento de pelos na radícula e os cotilédones ficaram mais aparentes devido a maior ruptura do envoltório seminal.

Figura 9. Germinação das sementes de milho (a e b) e do feijão (c), quinto dia.

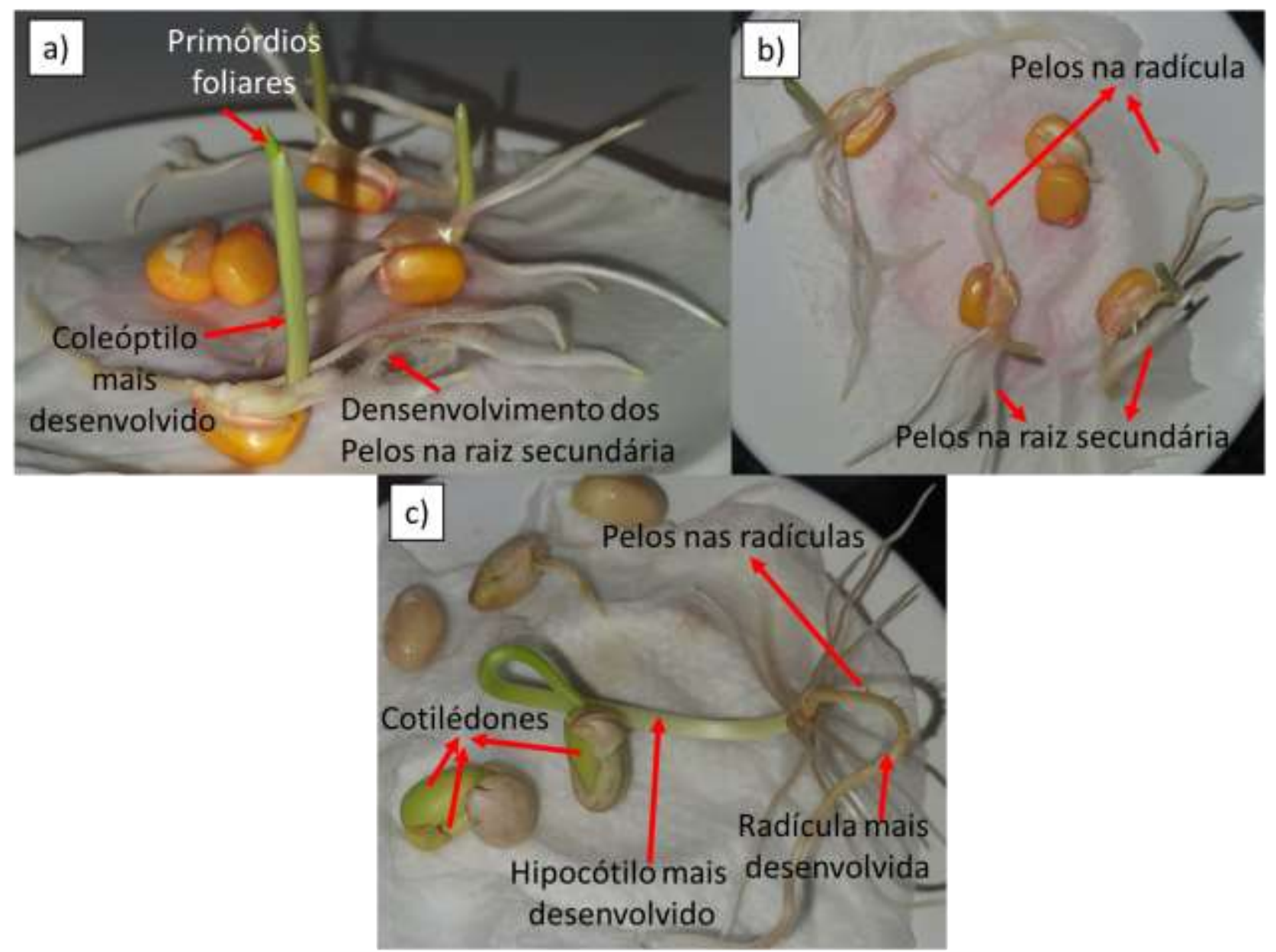

Fonte: Autor (2021).

No sexto dia, no milho (Figura 10a) ocorreu a continuidade do crescimento e desenvolvimento das raízes, a emissão de outros primórdios foliares, bem como o seu desenvolvimento nas outras sementes. No feijão (Figura 10b e 10c) ocorreu a emissão do primeiro primórdio foliar e o crescimento do hipocótilo.

Já no sétimo dia, as folhas e as raízes do milho se desenvolveram ainda mais (Figura 11a), e no feijão (Figura 11b), houve o aparecimento de outro primórdio foliar (folhas) e o crescimento das raízes continuaram. Após essa etapa, as plantas podem ser plantadas na terra para continuarem o seu pleno desenvolvimento. 
Research, Society and Development, v. 10, n. 4, e29510414120, 2021

(CC BY 4.0) | ISSN 2525-3409 | DOI: http://dx.doi.org/10.33448/rsd-v10i4.14120

Figura 10. Germinação das sementes de milho (a) e do feijão (b e c), sexto dia. As estrelas representam o primórdio foliar.

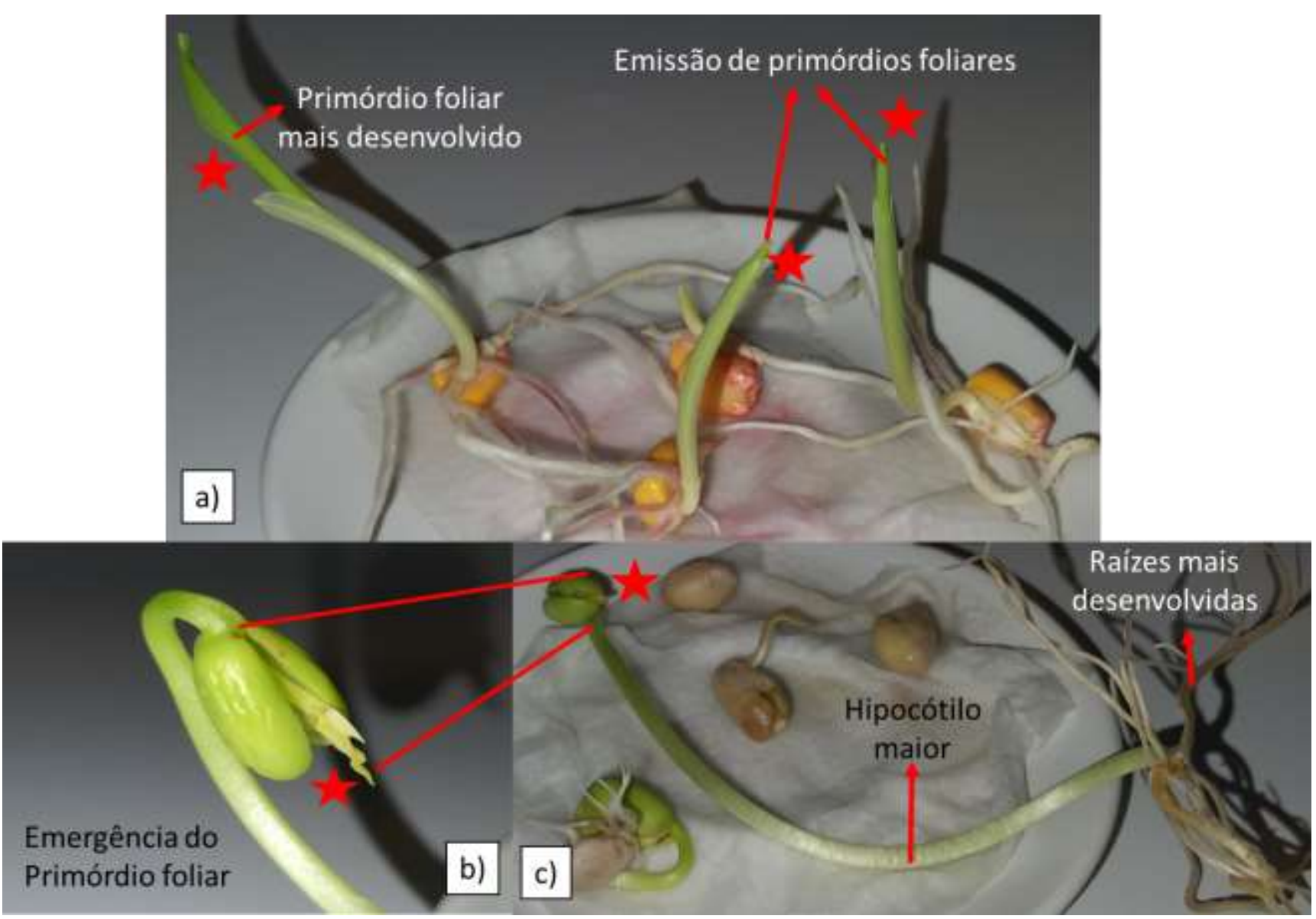

Fonte: Autor (2021).

Figura 11. Germinação das sementes de milho (a) e do feijão (b), sétimo dia.

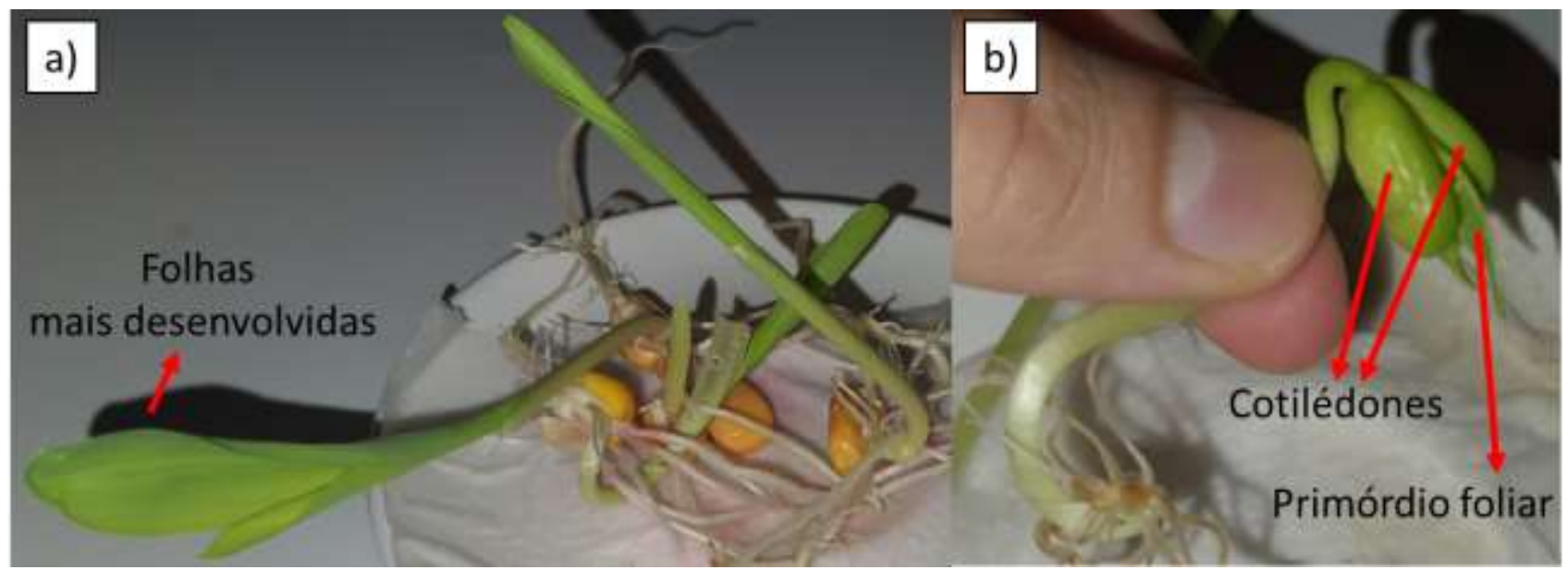

Fonte: Autor (2021).

Algumas sementes de plantas como por exemplo nas espécies de Mandioca de mesa (Manihot esculenta Crantz) e na Alfafa (Medicago sativa), temos a ocorrência do fenômeno chamado “dormência". Segundo Taiz et al. (2017), esse mecanismo é definido como a ausência de germinação mesmo se as condições ambientais forem satisfeitas, consistindo em um bloqueio temporal intrínseco ao término da germinação que fornece um período adicional para a dispersão da semente a distâncias 
geográficas maiores.

Segundo Peixoto, Pimenta \& Reis (2021), a escarificação é o processo utilizado para eliminar a dormência tegumentar, sendo realizada pelo tratamento das sementes com ácidos (escarificação química), água quente (escarificação térmica), atritos e lixas (escarificação mecânica), etc. Assim, todos esses processos fazem com que o material que compõe a estrutura do tegumento seja enfraquecido, arranhado e/ou quebrado, facilitando a embebição e o posterior lançamento da radícula ou da parte aérea.

$\mathrm{Na}$ tabela abaixo, estão as respostas da Tabela 3, proposta para enriquecer a discussão da segunda parte da atividade experimental.

Tabela 5. Características gerais das espécies estudadas.

\begin{tabular}{|c|c|c|c|c|}
\hline Características & \multicolumn{2}{|l|}{ Milho } & \multicolumn{2}{|c|}{ Feijão } \\
\hline Nome da espécie & \multicolumn{2}{|l|}{ Zea mays $\mathrm{L}$. } & \multicolumn{2}{|c|}{ Phaseolus vulgaris $\mathrm{L}$. } \\
\hline $\begin{array}{l}\text { Classificação botânica quanto aos } \\
\text { Cotilédones }\end{array}$ & $\begin{array}{l}\text { Monocotiledônea } \\
\text { Dicotiledônea }\end{array}$ & $\mathrm{X}$ & $\begin{array}{l}\text { Monocotiledônea } \\
\text { Dicotiledônea }\end{array}$ & $\mathrm{X}$ \\
\hline Tipo de germinação & \multicolumn{2}{|c|}{ Hipógea } & \multicolumn{2}{|c|}{ Epígea } \\
\hline Distribuição de vasos no caule & \multicolumn{2}{|c|}{$\begin{array}{c}\text { Feixes líbero-lenhosos } \\
\text { espalhados. }\end{array}$} & \multicolumn{2}{|c|}{$\begin{array}{l}\text { Feixes líbero-lenhosos } \\
\text { dispostos em círculos. }\end{array}$} \\
\hline Tipo de raiz & \multicolumn{2}{|c|}{ Fasciculada (cabeleira). } & \multicolumn{2}{|c|}{$\begin{array}{c}\text { Pivotante ou axial } \\
\text { (principal). }\end{array}$} \\
\hline Tipo de caule & \multicolumn{2}{|c|}{$\begin{array}{l}\text { Em geral sem crescimento } \\
\text { em espessura (bulbo, rizoma, } \\
\text { colmo). }\end{array}$} & \multicolumn{2}{|c|}{$\begin{array}{l}\text { Em geral com crescimento } \\
\text { em espessura (tronco). }\end{array}$} \\
\hline Tipo de nervação foliar & \multicolumn{2}{|c|}{$\begin{array}{c}\text { Costuma ser estreita, com } \\
\text { nervuras paralelas } \\
\text { (paralelinérvea). }\end{array}$} & \multicolumn{2}{|c|}{$\begin{array}{l}\text { Costuma ser palmada, com } \\
\text { nervuras em forma de rede } \\
\text { (reticulinérvea). }\end{array}$} \\
\hline
\end{tabular}

Fonte: Autor (2021).

Por fim, pode-se discutir com os alunos os mecanismos de dispersão das sementes, que conforme Júnior \& Sasson (2005), a história evolutiva das Angiospermas exibe grande diversidade de adaptações, utilizando os mais diferentes meios físicos e biológicos, proporcionando-lhes eficiente disseminação. Assim, os autores discutem que seus frutos desenvolveram estruturas especiais e capacidades relacionadas a diferentes meios disseminadores como a zoocoria (dispersão por animais), anemocoria (dispersão pelo vento) e hidrocória (dispersão pela água).

\section{Considerações finais}

Pela aula prática proposta, os alunos poderão observar como um teste simples e rápido pode determinar a viabilidade das sementes tanto em monocotiledôneas (milho) como em dicotiledôneas (feijão). Além da discussão de outros aspectos como a Bioquímica (identificação da estrutura e função de polissacarídeos - amido na semente) por meio do Lugol 5\%. A aula prática também permite trabalhar os conceitos inerentes à Fisiologia Vegetal no que tange ao processo de germinação das sementes nas plantas, diferenciando-se assim o mecanismo que ocorre nas monocotiledôneas e dicotiledôneas. 
Research, Society and Development, v. 10, n. 4, e29510414120, 2021

(CC BY 4.0) | ISSN 2525-3409 | DOI: http://dx.doi.org/10.33448/rsd-v10i4.14120

Neste sentido, conclui-se que a aula prática proposta possui potencial metodológico qualitativo para facilitar a aprendizagem dos alunos, resgatando na prática o que foi aprendido nas aulas teóricas de Biologia.

Como sugestões de abordagens futuras, será de grande relevância a proposta e a realização de outros experimentos no escopo da Botânica (aula prática guiada pelo professor sobre a dissecação de diversas estruturas florais e frutíferas das angiospermas), da Bioquímica (simulação da fotossíntese das plantas), além de outras áreas correlatas como a Fisiologia Vegetal, que nesse último caso, poderá ser proposto aos alunos uma aula prática sobre o Fototropismo, interferindo diretamente no processo de crescimento e desenvolvimento vegetal.

\section{Referências}

Bresinsky, A., Korner, C., Kadereit, J. W., Neuhaus, G., \& Sonnewald, U. (2012). Tratado de Botânica de Strasburger. (36a ed.), 1166p.

Bricia, V. (2014). Sobre a natureza da Ciência e o ensino. In Carvalho, A. M. P., (Org) Oliveira, C. M. A., Scarpa, D. L. Sasseron, L. H., Sedano, L., Silva, M. B., Capecchi, M. C. V. M., Abib, M. L. V. S., \& Bricia, V. Ensino de Ciências por investigação - condições para implementação em sala de aula. (111-128p). São Paulo, Cengage Learning.

Carvalho, N. M., \& Nakagawa, J. (2012). Sementes: Ciência, Tecnologia e Produção. (5a ed.), FUNEP, 590p.

Ferreira, G, L., Costa, V. C. da., \& Araujo, M, H. (2008). Diminuição do amido em bananas maduras: um experimento simples para discutir ligações químicas e forças intermoleculares. Encontro Nacional de Ensino de Química [Internet]. Curitiba: XIV ENEQ. http://www.quimica.ufpr.br/eduquim/eneq2008/resumos/R0950-1.pdf

Ferreira, R.L. (2010). Etapas do beneficiamento na qualidade física e fisiológica de sementes de milho (Dissertação de mestrado) Faculdade de Engenharia UNESP, Campus de Ilha Solteira, São Paulo, SP. Brasil. https://repositorio.unesp.br/bitstream/handle/11449/98722/ferrei ra_rl_me_ilha.pdf?sequence=1\&isAllowed=y

Gonçalves, T. M. (2021a). A guerra imunológica das células contra os patógenos: a proposta de um modelo didático tridimensional de baixo custo para simulação da resposta imune celular mediada por linfócitos $\mathrm{T}$ CD8+. Brazilian Journal of Development, 7(1), 4.854-4.860. https://www.brazilianjournals.com/index.php/BRJD/article/view/23099/18554

Gonçalves, T. M. (2021b). Permeabilidade da membrana plasmática celular da beterraba: uma proposta de aula prática no ensino médio. Research, Society and Development, 10(3), 1-9. https://rsdjournal.org/index.php/rsd/article/view/13479

Instituto Nacional de Estudos e Pesquisas Educacionais Anísio Teixeira, INEP (2019). Dados do censo escolar. http://portal.inep.gov.br/artigo//asset_publisher/B4AQV9zFY7Bv/content/dados-do-censo-escolar-noventa-e-cinco-por-cento-das-escolas-de-ensino-medio-tem-acesso-a-internet-masapenas-44-tem-laboratorio-de-ciencias/21206

Júnior, C. S., \& Sasson, S. (2005). Biologia: volume 2: Seres vivos: estrutura e função. (8a ed.), Saraiva, 527p.

Krasilchik, M. (2004). Prática de Ensino de Biologia. Edusp, 199p.

Laboratório Didático de Bioquimica (2021). Teste de Iodo. http://plone.ufpb.br/ldb/contents/paginas/teste-do-iodo

Marandino, M., Selles, S. E., Ferreira, M. F. (2009). Ensino de Biologia: histórias e práticas em diferentes espaços educativos. Editora Cortez, 215p.

Marcos, F. J., Cicero, S.M., \& Silva, W.R. (1987). Avaliação da qualidade das sementes. FEALQ, 230p.

Nabors, M. W. (2012). Introdução à Botânica. ROCA, 646p.

Peixoto, P. H. P.; Pimenta, M. R., \& Reis, L. B. (2021). Fisiologia vegetal uma abordagem prática em multimídia: manual do aluno. https://www.ufjf.br/fisiologiavegetal/files/2018/07/Manual-de-Aulas-Pr\%c3\%a1ticas-Fisiologia-Vegetal.pdf

Reece, J. B., Urry, L. A., Cain, M. L., Wasserman, S. A., Minorsky, P. V., \& Jackson, R. B. (2015). Biologia de Campbell, (10a ed.), Artmed, 1442p.

Sá, M. E., Oliveira, S. A., \& Bertolin, D. C. (2011). Roteiro prático da disciplina de produção e tecnologia de sementes: análise da qualidade de sementes. Cultura acadêmica, $114 \mathrm{p}$.

Taiz, L., Zeiger, E., Moller, I. M., \& Murphy, A. (2017). Fisiologia Vegetal, (6a ed.), Artmed, 858p.

Trivelato, S, F., \& Silva, R. L. F. (2011). Ensino de Ciências. Cengage Learning, 135p.

Wikipedia (2021a). Amilose. Foto de NEUROtiker https://pt.wikipedia.org/wiki/Amilose\#: :text=Amilose\%20\%C3\%A9\%20uma\%20mol\%C3\% A9cula\%20formada,pol\%C3\%ADmero\%20que\%20forma\%20o\%20amido.

Wikipedia (2021b). Amilopectina. Foto de NEUROtiker. https://pt.wikipedia.org/wiki/Amilopectina\#: :text=A\%20amilopectina\%2C\%20mol\%C3\%A 9cula\%20mais\%20abundante,liga\%C3\%A7\%C3\%B5es\%20\%CE\%B1\%2D1\%2C6. 